\title{
Application of On-line Detection Technology in Shanghai Power Grid
}

\author{
Jun Liu ${ }^{1, a}$, Huaxin Wang ${ }^{2, b}$, Tianshui Xue ${ }^{2}$, Ruchen Zhang ${ }^{2}$ \\ ${ }^{1}$ Shanghai Electric Power Research Institute, Shanghai, 200090, China \\ ${ }^{2}$ Institute of electric engineering, Shanghai University of Electric Power, Shanghai, 200090, China \\ aemail: 15165331940@163.com, bemail: 2009000032@shiep.edu.cn
}

Keywords: On-line Detection Technology; Shanghai Distribution Network; Development Plan

\begin{abstract}
The common on-line detection methods are introduced in this paper generally. Additionally, the application of on-line detection in shanghai distribution network is mainly analyzed and its further popularization is well programmed.
\end{abstract}

\section{The Meaning of On-line Detection}

Distinct from the long-term continuous online monitoring, on-line detection technology is a method that the state variables are acquired in a short period by means of portable measuring devises while the electrical equipments are operating. On-line detection can discover the latent fault of power equipment in advance and then avoid equipment accident by taking critical measures. The comprehensive deep application of the on-line detection enables to save efforts and resources efficiently so as to avert the economic loss that long-time maintenance causes, therefore the overall and high efficient application of this technology can achieve an economy benefits.

The method of on-line detection is mainly accorded with the characteristics appeared with electrical equipment fault at first and with the other factors like the capacity of electrical power equipment, structure, volume, price and etc. At present, the common used method of on-line detection in distribution network is the partial discharging detection that mainly contains infrared thermometry, transient grounding voltage and ultrasonic and ultrahigh frequency partial discharge detection technology. Infrared imaging technology is used in the surface temperature measurement and fault heating detection of all the electrical appliances and in the thermal image analysis during the maintenance; Ultraviolet thermometry is used in the examination of corona of power transmission and transformation equipments; Switching on-off current wave analysis technology detects the continuous current of operating arrestor every year before the thunderstorm season; Chromatographic analysis technique of transformer oil of oil-filled equipments develop widely and effectively; Having an analysis of gas's humidity, purity and decomposition products on the SF6 circuit breaker and GIS; Having an oil pressure determination on electric cable and using the oscillation wave location technology to have a state monitoring of electric cable; Detecting the grounding current in the earth loop by using current transformers or clamp ammeters; Flowmeter is used in the flow detection of cycle oil system of large transformers, etc.

This essay mainly introduces the application of on-line detection technology in shanghai's distribution network and gives instructive suggestions of this application next according to the current condition.

\section{Common Technology of Detection}

With the development and improvement of measurement technology, on-line detection technology becomes various. Nowadays, several mainly kinds of new technologies that are widely used are as follows:

(1) High frequency partial discharging monitoring technology. It collects, analyzes and judges partial discharging signals of the frequency between $3 \mathrm{MHz}$ and $30 \mathrm{MHz}$. It extracts signals from bushing tap earth wire, high-voltage earth wire and the end of arrester.

(2) Ultrasonic partial discharge detection technology. It collects, analyzes and judges partial 
discharging signals of the frequency between $20 \mathrm{MHz}$ and $200 \mathrm{MHz}$. On the contrary to the traditional detection method such as electric pulse, this method has little electrical interference and enables to realize remote wireless measurement.

(3) Ultrahigh frequency partial discharge detection technology. It collects, analyzes and judges partial discharging signals of the frequency between $300 \mathrm{MHz}$ and $3 \mathrm{GHz}$, which is mainly used in the detection of GIS and electric cable. Characteristic parameters of ultrahigh frequency discharge pulse mainly have signal amplitude, discharge initial point and pulse interval, which can be all used in defect recognition.

(4) Transient grounding voltage detection technology. When partial discharge occurs, it produces the immediate grounding voltage on the grounding mental surface, which can spread to all directions along the mental surface. By detecting the grounding voltage realizes the judgment and location of electrical appliances' partial discharge.

(5) Relative dielectric loss factor or relative capacity ratio detection technology. The former one means that having tangent calculation on the difference between two capacitive-type equipments' end current including equipments of same phase and heterogeneous, which is called relative electric loss factor after conversion. When coming to the standard of default, a power failure will appear and the experiment should be done. However, the latter one means the ratio of capacitance value of two capacitive-type equipments' end current, and then the same goes when coming to the standard of default.

(6) SF6 leakage inspection imaging method technology. Realize the accurate location of live leak detection and leak point of SF6 appliances by using imaging method like laser imaging method and infrared imaging method.

\section{Explored Works in Shanghai Power Grid}

The state gird suggests to generalize the on-line detection method on those major equipments in power system such as transformers, insulating bushing, current and voltage transformers, coupling capacitor, arrester, switchgear, open-type SF6 circuit breaker, electric cable and GIS.

At present, according to the wide application of those on-line detection methods suggested by the state grid, the results are as follows.

Tab.1. Results of detection technologies

\begin{tabular}{|c|c|c|c|c|c|c|}
\hline Voltage Class & \multicolumn{3}{|c|}{$\geq 110 \mathrm{kV}$} & \multicolumn{3}{|c|}{$\leq 35 \mathrm{kV}$} \\
\hline Device Type & switch & transformer & $\begin{array}{l}\text { electric } \\
\text { cable }\end{array}$ & switch & transformer & $\begin{array}{l}\text { electric } \\
\text { cable }\end{array}$ \\
\hline UHF PD & $\sqrt{ }$ & $\sqrt{1}$ & $\sqrt{ }$ & $\sqrt{ }$ & $\sqrt{ }$ & $\sqrt{ }$ \\
\hline Ultrasonic Wave PD & $\sqrt{ }$ & $\sqrt{ }$ & $\sqrt{ }$ & $\sqrt{ }$ & $\sqrt{ }$ & $\sqrt{ }$ \\
\hline Transient Earth Voltage & & & & $\sqrt{ }$ & & \\
\hline $\begin{array}{c}\text { Ultrasonic Assisted } \\
\text { Electrocatalysis Wave Method }\end{array}$ & $\sqrt{ }$ & $\sqrt{ }$ & $\sqrt{ }$ & $\sqrt{ }$ & $\sqrt{ }$ & $\sqrt{ }$ \\
\hline $\begin{array}{l}\text { Switching Control Current } \\
\text { Analysis }\end{array}$ & $\sqrt{ }$ & & & $\sqrt{ }$ & & \\
\hline DGA & & $\sqrt{1}$ & & & $\sqrt{ }$ & \\
\hline Oil Pressure in Electric Cable & & & $\sqrt{ }$ & & & \\
\hline $\begin{array}{c}\text { Partial Discharge Location of } \\
\text { Electric Cable with Oscillating } \\
\text { Voltage }\end{array}$ & & & & & & $\sqrt{ }$ \\
\hline $\begin{array}{c}\text { Infrared Temperature } \\
\text { Measurement }\end{array}$ & $\sqrt{ }$ & $\sqrt{ }$ & $\sqrt{ }$ & $\sqrt{ }$ & $\sqrt{ }$ & $\sqrt{ }$ \\
\hline $\begin{array}{c}\text { Ultraviolet Temperature } \\
\text { Measurement }\end{array}$ & $\sqrt{ }$ & & & $\sqrt{ }$ & & \\
\hline
\end{tabular}

State detection technology has acquired achievement in the application in distribution network in shanghai: 
(1) Various online monitoring system have been placed like oil chromatogram, GIS Ultrahigh frequency partial discharge, circuit breaker, SF6, oil pressure of electric cable and cable and fiber's temperature measurement in Xuhang, Pujian and Jinan, therefore numerous experience of managing and judging have been accumulated.

(2) On-line detections have been exploited such as transient ground radio wave, detection location of partial discharge of the combination of acoustic and electronic parameters, infrared, ultraviolet, decomposition of SF6 and leak detection by using SF6 laser, which prevent several accidents of appliances successfully and accumulate a large quantity of data and judging experience.

\section{Development Plan}

According to the development of various technology of detection, separate on-line detection technology into three levels: constant perfection, application and dissemination and technical reserve in order to cope with different development plans of detection technology, which are as the following chart.

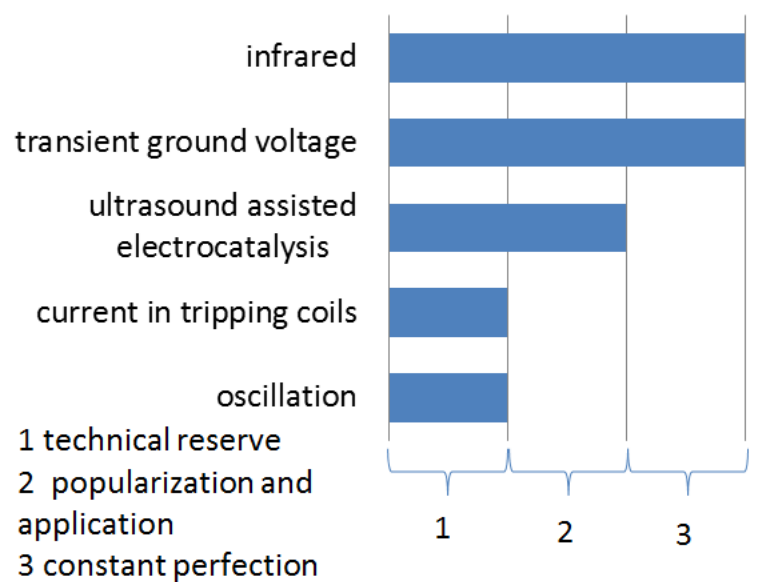

(a) Switchgears

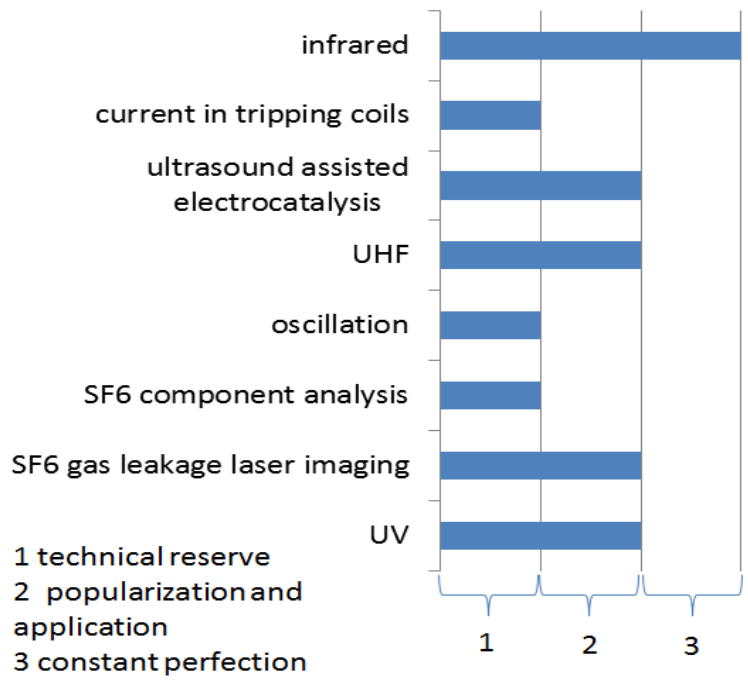

(c) GIS/ Circuit Breaker

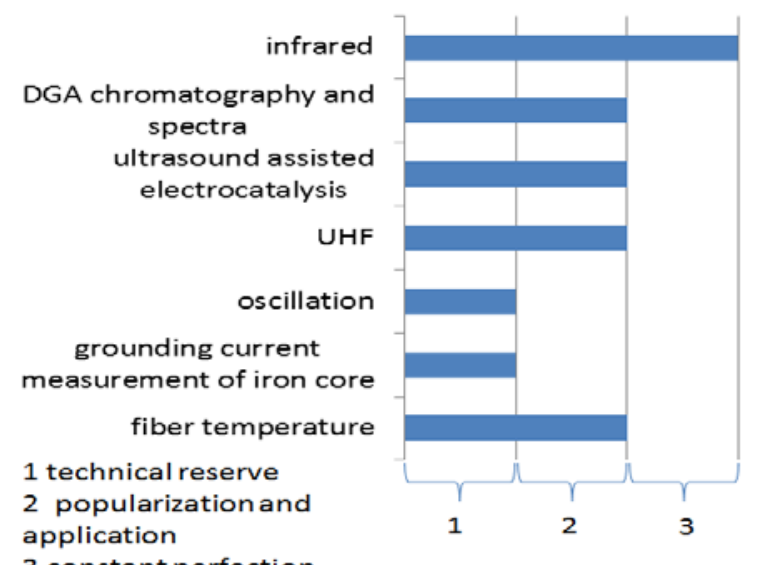

(b) Transformers

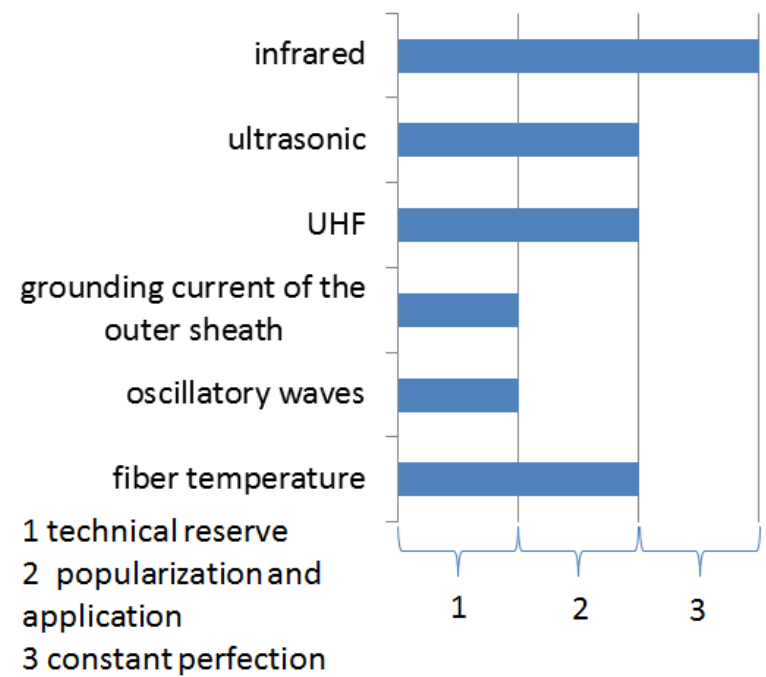

(d) Electric Cable

Fig.1. Development plan of on-line detection technology

Summarizing the development plan of the technology of each detective items as above comes to the statistics as follows. 
Tab.2. statistical table of on-line detection development

\begin{tabular}{c|c|c|c|c}
\hline items & improvement & $\begin{array}{c}\text { Application and } \\
\text { dissemination }\end{array}$ & Technical reserve & total \\
\hline switchgear & 2 & 1 & 2 & 5 \\
\hline transformer & 1 & 4 & 2 & 7 \\
\hline $\begin{array}{c}\text { GIS/circuit } \\
\text { breaker }\end{array}$ & 1 & 4 & 2 & 6 \\
\hline $\begin{array}{c}\text { Electric } \\
\text { cable(joint) }\end{array}$ & 1 & 3 & 3 & 6 \\
\hline
\end{tabular}

According to the chart, the on-line detection method used in the GIS or circuit breaker has eight, which is the most, and then the on-line detection method used in the development of switchgear has two. The method used in transformer, GIS/circuit and electric cable only has one. However, the method used in the application and dissemination of transformers and GIS/circuit breaker is the most, which has four while in the electric cable has three.

\section{Conclusion}

1) Enhance the application and dissemination of the on-line detection of transformers, GIS/circuit breaker and electric cable and carry out one when it completes.

2) Improve each detection technology continuously so as to extend and apply this technical reserve and prepare for the experiment earlier.

\section{References}

[1] Liao Tianming. Review of Condition Monitoring Technology and Condition Maintenance Work in China[J]. Distribution \& Utilization, 2012, 29(4): 13-16.

[2] Deng Wanting. Application of on-line detection technology in the mode of condition based on maintenance in Hubei Smart Grid[J]. Hubei Electric Power, 2010, 34(A01): 29-31.

[3] Fan Wenbo, Sheng Wanxing, Gao Yuan.etc Research on Application of charged detection technology in the state of distribution in equipment maintenance[J]. Electric Safety, 2013, 32(17): 64-67.

[4] Yang Xianzhi, Zhang Jian. Application of $10 \mathrm{kV}$ Switchgear Partial Discharge Detecting Based on Ultrasonic and TEV Technology in the Power Distribution Network[J]. Electric Power Science and Engineering, 2011, 27(6): 71-75.

[5] QIAN Yong, HUANG Chengjun, JIANG Xiuchen, etc. Current Status and Development of PD Online Monitoring Technology in GIS[J]. High Voltage Apparatus, 2004, 40(6): 453-456.

[6] WANG Guoli, HAO Yanpeng, LI Yan ming. Present and furute development of partial discharge detection in power transformers[J]. Advanced Technology of Electrical Engineering and Energy, 2001, 20(2): 52-57. 